\title{
A PARAMETRIC STUDY ON THE FAILURE OF BONDED SINGLE-LAP JOINTS OF GFRE COMPOSITE AND ALUMINUM
}

\author{
M. A. GHANEM \\ Lecturer, Mech, Dept., Faculty of Industrial Education, Suez Canal University.
}

\begin{abstract}
This paper investigates the effect of bonding pressure, overlap length and adherent thickness on the strength and failure load of the single-lap joints of dissimilar materials (GFRE composite and aluminum). Eighteen groups of joints made of glass fiber epoxy composite laminates and $\mathrm{Al}$ have been manufactured. The stacking sequences $[0 / \pm 45 / 90]$ and $[0 / \pm 45 / 90]$ s were used to manufacture $2 \mathrm{~mm}$ and $4 \mathrm{~mm}$ thick GFRE composite laminates, whereas $\mathrm{Al}$ thickness was $1.5 \mathrm{~mm}$ and $3 \mathrm{~mm}$. In all cases, the CY219 adhesive thickness was $0.12 \pm 0.02 \mathrm{~mm}$, and the specimen width was $25 \mathrm{~mm}$. Besides, various values of bonding pressure [1, 2, 3, 4, 5, 6 atm.] were applied.
\end{abstract}

The experimental results show that, the failure load and strength of the joint increase with bonding pressure up to $4 \mathrm{~atm}$. Higher bonding pressures do not considerably affect the failure load and strength. Hence, a bonding pressure of 4 atm. was found suitable for bonding composite to aluminum. Moreover, the failure load increased and the bonding strength decreased with increasing the overlap length. However, the increase of failure loads slightly at overlap lengths larger than $30 \mathrm{~mm}$. Also, increasing the adherent thickness resulted in an increase of the failure load. Finally, the failure mode of tested joints was composite delaminating.

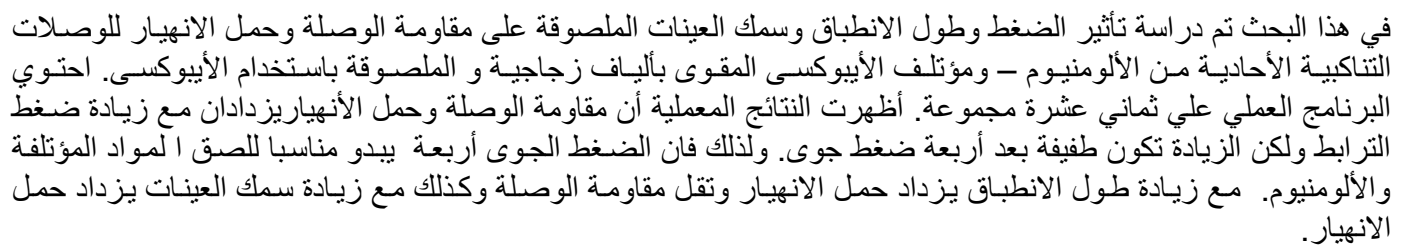

KEYWORDS: Single-Lap Bonded Joint, Dissimilar Materials, Failure

\section{INTRODUCTION}

Glass and carbon fiber-epoxy composite materials have been used in advanced engineering structures such as spacecraft, aircraft, automobiles, transmission shafts and robot structures, because of their high specific stiffness and strength, and high wear resistance. Mechanical joints such as bolted, pinned, or riveted joints (both in metal and composites) are most common. They are quite simple and suitable for disassembly. Mechanical joints, however, inherently result in micro and/or local damage of the composite laminate during the manufacturing process. Consequently, strength degradation of the structure is induced. On the other hand, adhesive bonding is another joining method that is increasingly being utilized and it's a very comfortable method of joining two materials with different stiffness like metal and composite [1-3]. The major advantage of adhesive bonding is that fastening holes and fasteners, which are a source of stress concentration and weight increase, are no longer necessary. As a result, the stress distribution in adhesively bonded joints is relatively uniform compared to that in mechanical joints. However, adhesive bonding has some disadvantages; because they are difficult disassembly, sensitivity of the bonding strength to environmental factors, such as temperature and humidity, and high cost of surface preparation, as well as the low inter-laminar strength of composite adherend [4-5]. It has been shown [5-6] that, the bond strength between composite and metallic structure is significantly affected by the 
surface preparation of the composite and metallic structure. Design of adhesively bonded joints with composite adherend is also known to be difficult, due to a lack of suitable failure criteria and the low interlaminar strength of composite adherend. Singlelap bonded joints have been studied through experimental and numerical approaches [7-9]. The stress and strain distributions across the adhesive thickness in composite single-lap joints was studied [10]. They indicated that, both tensile peel and shear stresses at the bond free ends changed significantly across the adhesive thickness. Single-lap bonded joints with cross-ply adherend were examined [11]. It has been shown by numerical analysis that, the surface layer orientation influenced the failure mode and strength. They also showed that, the failure load increases with increasing the ratio of the overlap length to adhesive thickness. On the other hand, the influence of the bonding method on failure mode and strength of composite single-lap bonded joints was studied [12]. The failure strength was not always proportional to the adhesion strength of the adhesive. Fatigue behavior and damage of joints were also investigated [13-17]. Different methods to predict the failure loads of single-lap joints have been investigated [18-20]. The composite-to-aluminum joints in terms of their stiffness behavior due to fracture was studied [21]. A theoretical model was proposed to predict both the maximum stiffness of joints and the rate of stiffness loss with crack growth. They reported that, flexible adhesives significantly delay crack initiation and final failure. Shin and lee [22] performed a three dimensional finite element analysis considering thermal load of co-cured single lap and double lap bonded joints without any additional adhesive. The predicted failure load of single lap bonded joints by the Ye-criterion was in good agreement with experimental results. However, applying the Tsai-Wu criterion was better for double lap bonded joints.

The main objective of this work is to investigate the influence of the bonding pressure, the overlap length, and the adherent thicknesses on the failure load and failure mode of single lap bonded joints of dissimilar materials (GFRE composite and aluminum).

\section{EXPERIMENTAL WORK}

\subsection{Specimen Preparation}

Eighteen groups of test specimens have been prepared, each of which consisted of five specimens. First six groups were made under six different bonding pressures $(1,2,3,4,5$, and 6 atm.) using a constant overlap length $b=20 \mathrm{~mm}$, and constant thicknesses of aluminum and composite, $\mathrm{ta}=1.5 \mathrm{~mm}$ and $\mathrm{tc}=2 \mathrm{~mm}$, respectively. Second six groups were prepared using various overlap lengths b $(15,20,25$, 30,35 , and $40 \mathrm{~mm}$ ) at a constant bonding pressure $\mathrm{p}$ $=4 \mathrm{~atm}$. Last six groups were designed to study the effect of adherent thicknesses by increasing ta from 1.5 to $3 \mathrm{~mm}$ and tc from 2 to $4 \mathrm{~mm}$. Two different stacking sequences $[0 / \pm 45 / 90]$ and $[0 / \pm 45 / 90]$ s were used for glass fiber reinforced epoxy (GFRE) composite. The composite laminates with 2 and 4 $\mathrm{mm}$ thickness were fabricated using hand lay-up technique. The stacking sequence $[0 / \pm 45 / 90]$ was used for thin specimens $(2 \mathrm{~mm})$ while the stacking sequence $[0 / \pm 45 / 90] \mathrm{s}$ was used to manufacture thick specimens $(4 \mathrm{~mm})$. The thickness of aluminum was $1.5 \mathrm{~mm}$ and $3 \mathrm{~mm}$, for thin and thick specimens, respectively. The brittle adhesive material CY219 epoxy was used to bond aluminum and composite. A typical test specimen's configuration and manufacture are shown in Figs.1, 2 where the overlap length between the composite-to-aluminum plates is denoted as "b" and the thickness of the aluminum and composite are denoted as "ta" and "tc", respectively. The configuration is based on the ASTM standards D1002-01 for metal-to-metal single-lap joints, and D5868-01, which is intended to complement D100201 and extends the application to composite-tocomposite single-lap joints. Detailed dimensions of the specimens are given in table 1 . The width of all specimens was $25 \mathrm{~mm}$. The experimental program included eighteen groups, Table 1, each of which consisted of five test specimens. To study the effect of bonding pressure, the first six groups were prepared under different bonding pressures ( 1 to 6 atm.) controlled directly in an autoclave. The overlap length was $20 \mathrm{~mm}$, while the thickness of aluminum ta was $1.5 \mathrm{~mm}$, and that of composite tc was $2 \mathrm{~mm}$. To investigate the influence of overlap length on the failure load and strength of bonded joints, the second six groups were of different overlap

lengths $15,20,25,30,35$ and $40 \mathrm{~mm}$. The bonding pressure was 4 atm., while ta and tc were the same as for the first six groups. The last six groups were designed to study the effect of adherent thicknesses by increasing ta from $1.5 \mathrm{~mm}$ to $3 \mathrm{~mm}$ and tc from 2 to $4 \mathrm{~mm}$. The overlap length varied as in the second six groups. In all cases, the adhesive thickness was in the range $0.12 \pm 0.022 \mathrm{~mm}$. The bonding surface areas have been, first, ground using abrasive papers, then cleaned with acetone. The composite was then bonded with the aluminum plate using CY219 epoxy adhesive (youngs modulus equal 3.4 GPa and tensile yield strength equal $34 \mathrm{MPa}$ \} and cured at a room temperature.

\subsection{Tensile Testing}

Test specimens have been subjected to tensile loading using a universal testing machine until fracture at room temperature. The machine crosshead speed during all tests was $2 \mathrm{~mm} / \mathrm{min}$. Five specimens 
were tested for each test condition and the average value was used for plotting the different relationships.

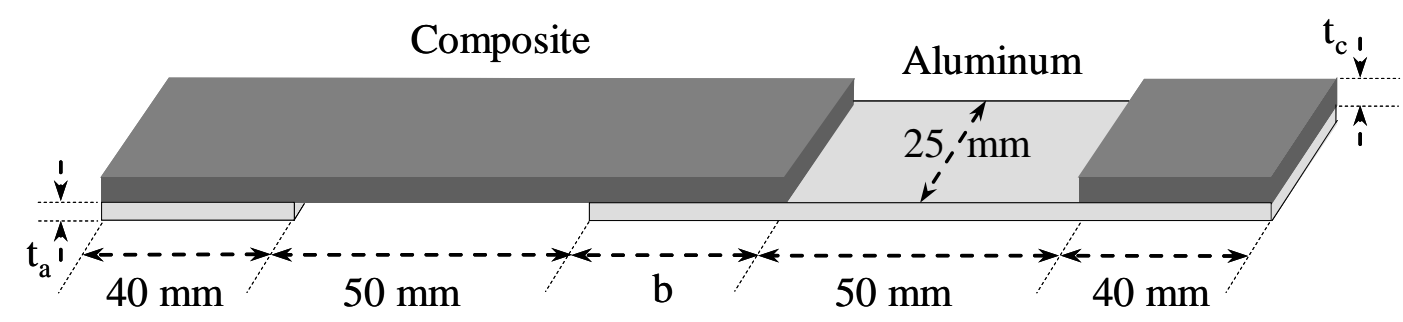

Fig.1: Configuration of a typical single-lap bonded joint.

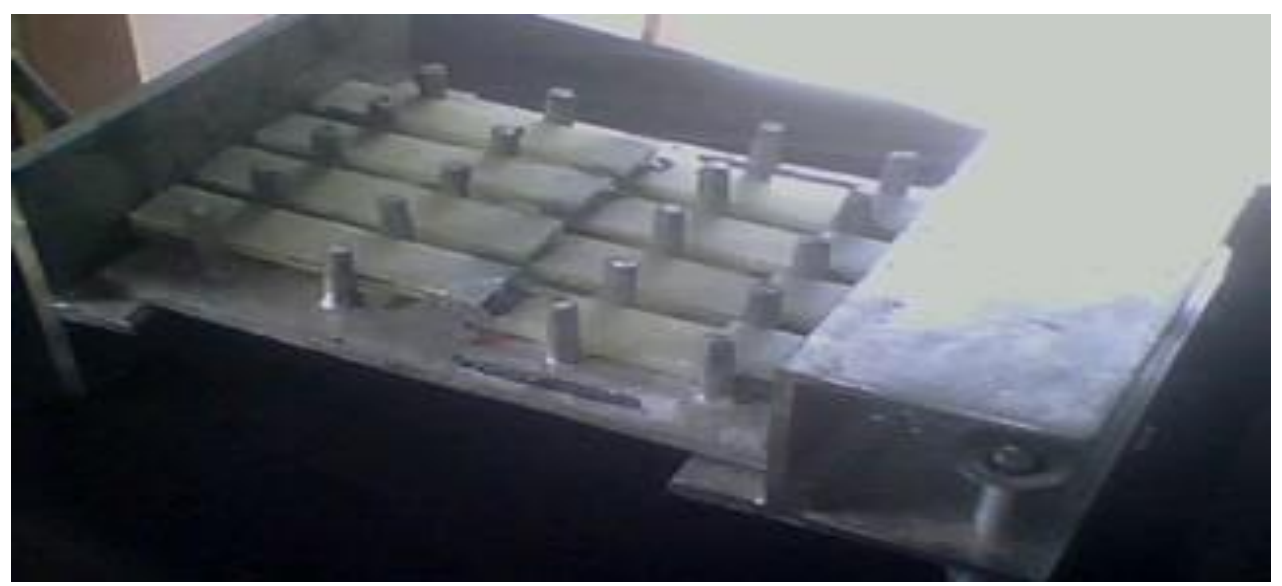

Fig.2. Manufacture of mixed adhesive joint

Table.1. Dimensions of composite-to-aluminum single-lap bonded joint specimens

\begin{tabular}{|c|c|c|c|c|c|c|}
\hline Group & $\begin{array}{c}\text { Bonding } \\
\text { pressure, } \\
\text { atm. }\end{array}$ & $\begin{array}{l}\text { Overlap } \\
\text { length } \\
\text { b, mm }\end{array}$ & $\begin{array}{c}\text { Aluminum } \\
\text { thickness } \\
\mathbf{t}_{\mathbf{a}}, \mathbf{m m}\end{array}$ & $\begin{array}{c}\text { Composite } \\
\text { thickness } \\
\mathbf{t}_{\mathrm{c}}, \mathbf{m m}\end{array}$ & $\begin{array}{c}\text { Adhesive } \\
\text { thickness, } \\
\text { mm }\end{array}$ & $\begin{array}{c}\text { Overall specimen } \\
\text { thickness } \\
\text { mm }\end{array}$ \\
\hline$\overline{11}$ & $\overline{\overline{1}}$ & 20 & $\overline{1.5}$ & $\overline{2}$ & 0.111 & 3.611 \\
\hline 2 & 2 & 20 & 1.5 & 2 & 0.131 & 3.631 \\
\hline 3 & 3 & 20 & 1.5 & 2 & 0.120 & 3.620 \\
\hline 4 & 4 & 20 & 1.5 & 2 & 0.120 & 3.620 \\
\hline 5 & 5 & 20 & 1.5 & 2 & 0.140 & 3.640 \\
\hline 6 & 6 & 20 & 1.5 & 2 & 0.142 & 3.642 \\
\hline 7 & 4 & 15 & \begin{tabular}{ll|}
1.5 \\
\end{tabular} & 2 & 0.112 & 3.612 \\
\hline 8 & 4 & 20 & 1.5 & 2 & 0.113 & 3.613 \\
\hline 9 & 4 & 25 & 1.5 & 2 & 0.102 & 3.602 \\
\hline 10 & 4 & 30 & 1.5 & 2 & 0.195 & $\mathbf{3 . 6 9 5}$ \\
\hline 11 & 4 & 35 & 1.5 & 2 & 0.101 & 3.601 \\
\hline 12 & 4 & 40 & 1.5 & 2 & 0.199 & 3.699 \\
\hline 13 & 4 & 15 & 3 & 4 & $\overline{0.110}$ & 7.110 \\
\hline 14 & 4 & 20 & 3 & 4 & 0.140 & 7.140 \\
\hline 15 & 4 & 25 & 3 & 4 & 0.120 & 7.120 \\
\hline 16 & 4 & 30 & 3 & 4 & 0.100 & 7.100 \\
\hline 17 & 4 & 35 & 3 & 4 & 0.110 & 7.110 \\
\hline 18 & 4 & 40 & 3 & 4 & 0.130 & 7.130 \\
\hline
\end{tabular}




\section{RESULTS AND DISCUSSION}

\subsection{Effect of Bonding Pressure}

Load displacement diagrams for groups 1 to 6 under various bonding pressures $(1,2,3,4,5,6$ atm.), at constant values of $\mathrm{Al}$ and composite thicknesses and overlap length, are illustrated in Fig.3. The relation between the applied load and displacement is, in general, nonlinear. Besides, the maximum strength and failure load increase with increasing the bonding pressure. The joint strength and failure load are plotted against the bonding pressure at $\mathrm{ta}=1.5, \mathrm{tc}=2$, and $\mathrm{b}=20 \mathrm{~mm}$., as shown in Fig.4. The figure indicates that, the joint strength and failure load increase effectively with bonding pressure $\mathrm{p}$ up to $4 \mathrm{~atm}$. At higher pressures, the rate of increase becomes lower. Hence, $4 \mathrm{~atm}$. is considered appropriate for present work.
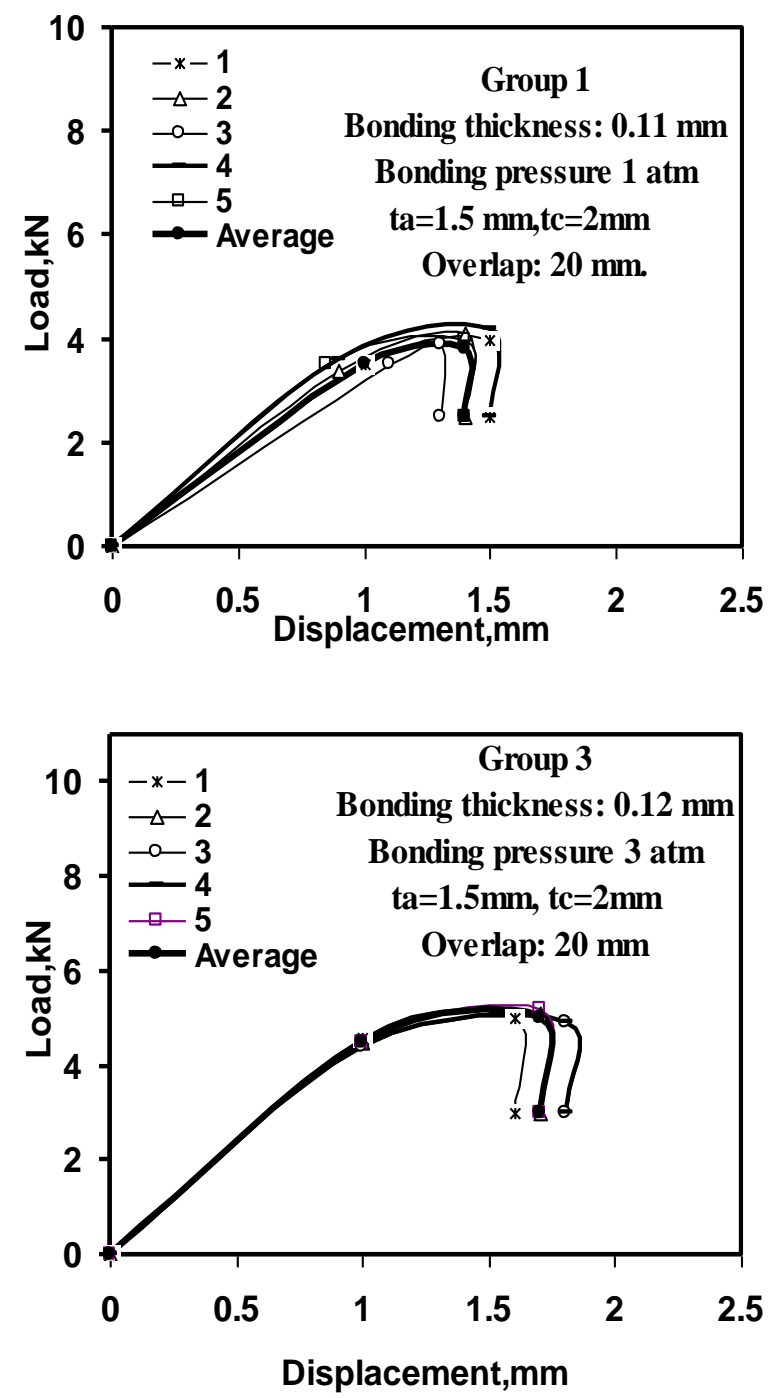

\subsection{Effect of Overlap Length}

The load-displacement diagrams of the second six groups with various overlap length $(15,20,25,30,35$, and $40 \mathrm{~mm})$ are plotted in Fig.5. Group7 with $15 \mathrm{~mm}$ overlap length shows an approximately linear relationship up to failure load, then the load drops suddenly. This is similar to previous observation [12] for composite-tocomposite single-lap bonded joints of $20 \mathrm{~mm}$ overlap length. The maximum failure load and the maximum strength for group 7 are about $4.5 \mathrm{KN}$ and $12 \mathrm{MPa}$, respectively. On the other hand, specimens of overlap lengths greater than $15 \mathrm{~mm}$ (groups 8 to 12) show linear load-displacement relationships in the first part followed by nonlinear relationships. Seong et al. [2] have indicated that, the plastic deformation of aluminum was responsible for the nonlinear behavior of the load-displacement curve.
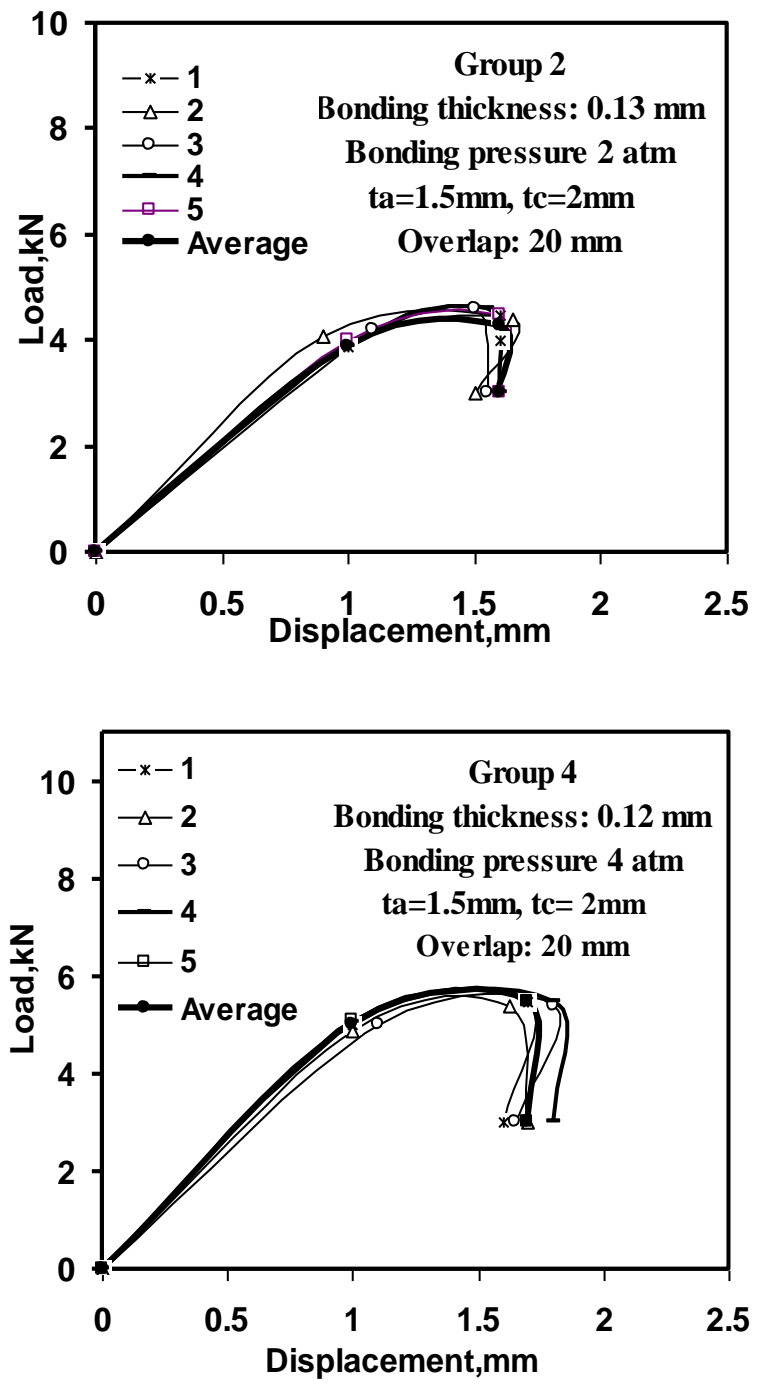

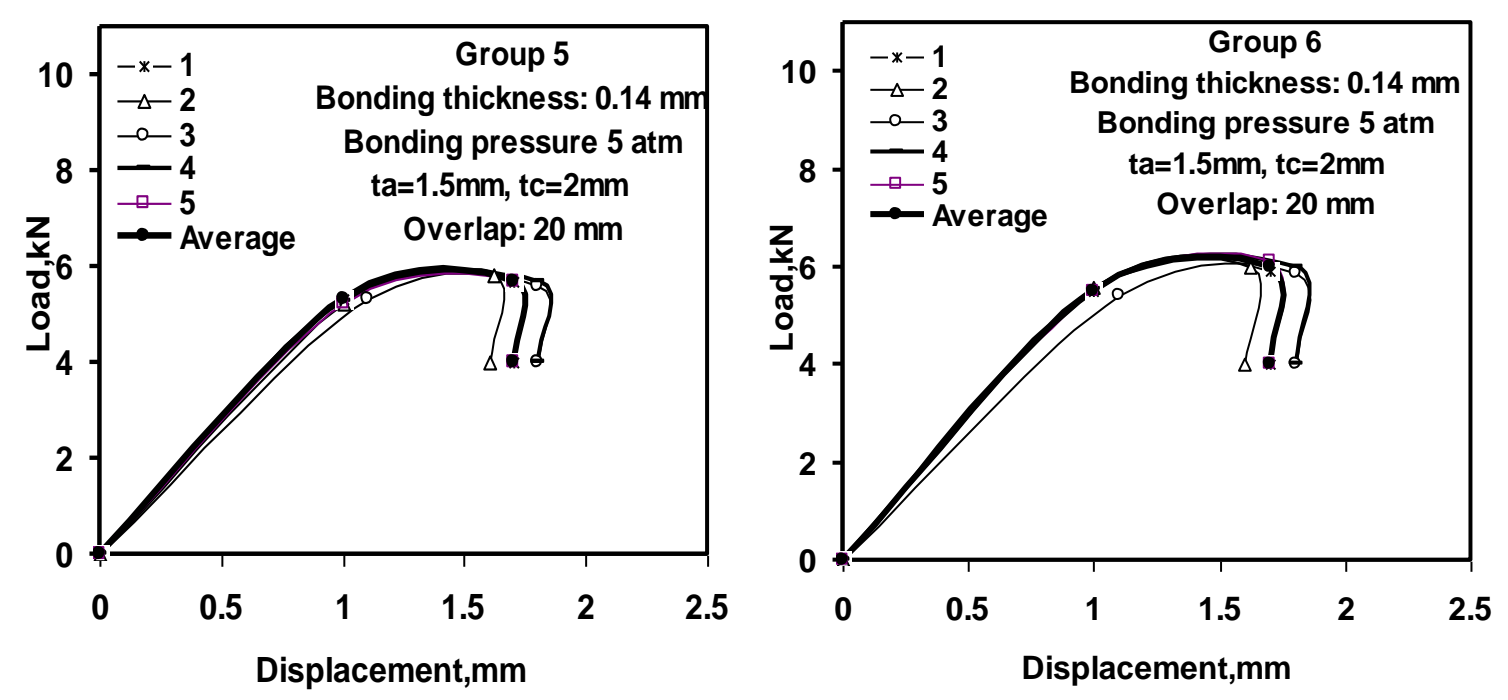

Fig.3. Load-displacement curve of bonded joints with different bonding pressure.
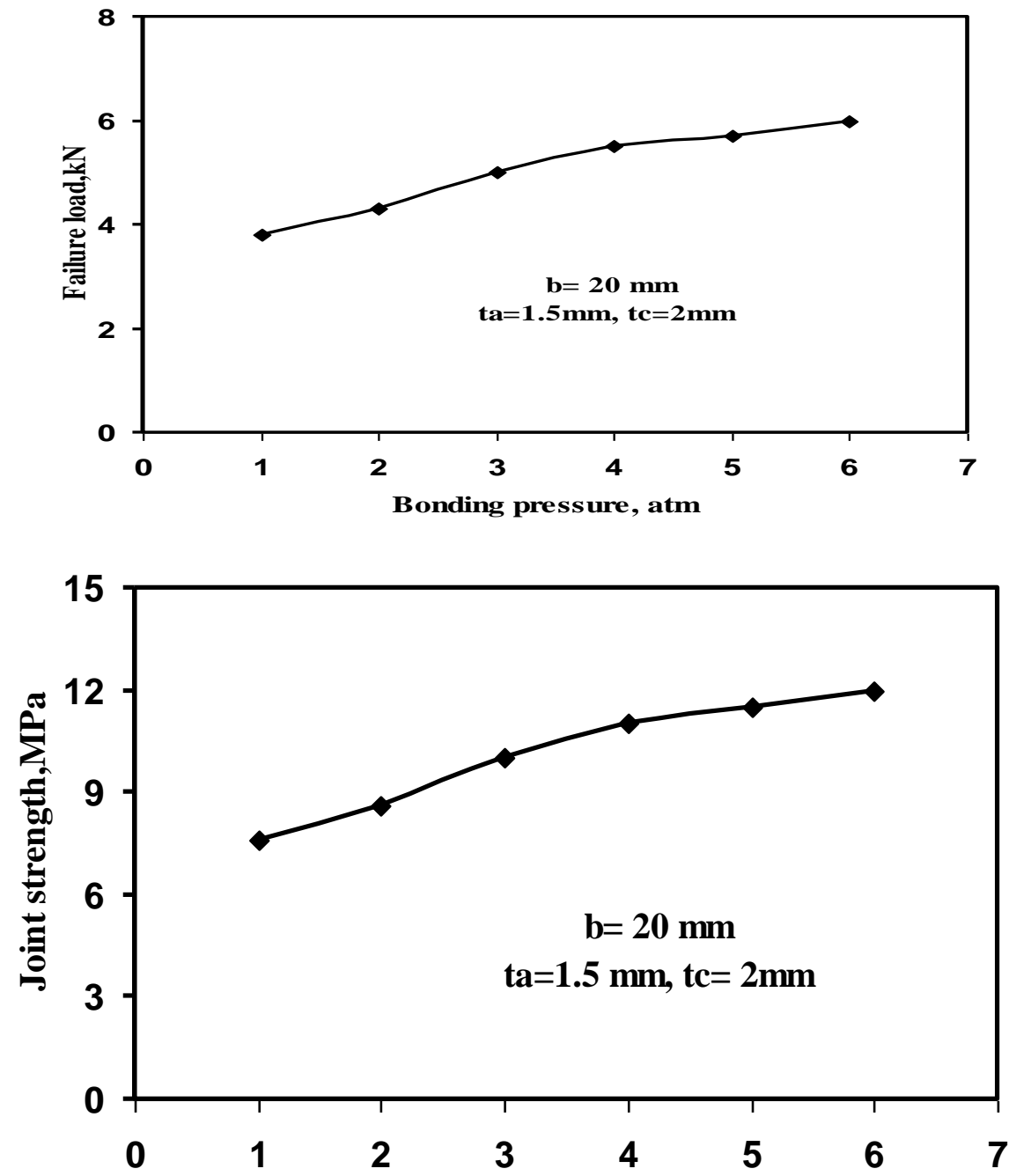

Bonding pressure, atm

Fig.4. Joint strength and Failure loads of bonded joints vs. bonding pressure. 
The bonded joint strength and failure load are plotted against the overlap length, as shown in Fig. 6. The figure indicates that, the joint strength decreases and the failure load increases with increasing the overlap length. Moreover, it is also shown that, the failure load is not linearly proportional to the overlap length. The increase of failure load diminishes with increasing the overlap length, until it becomes negligibly small.
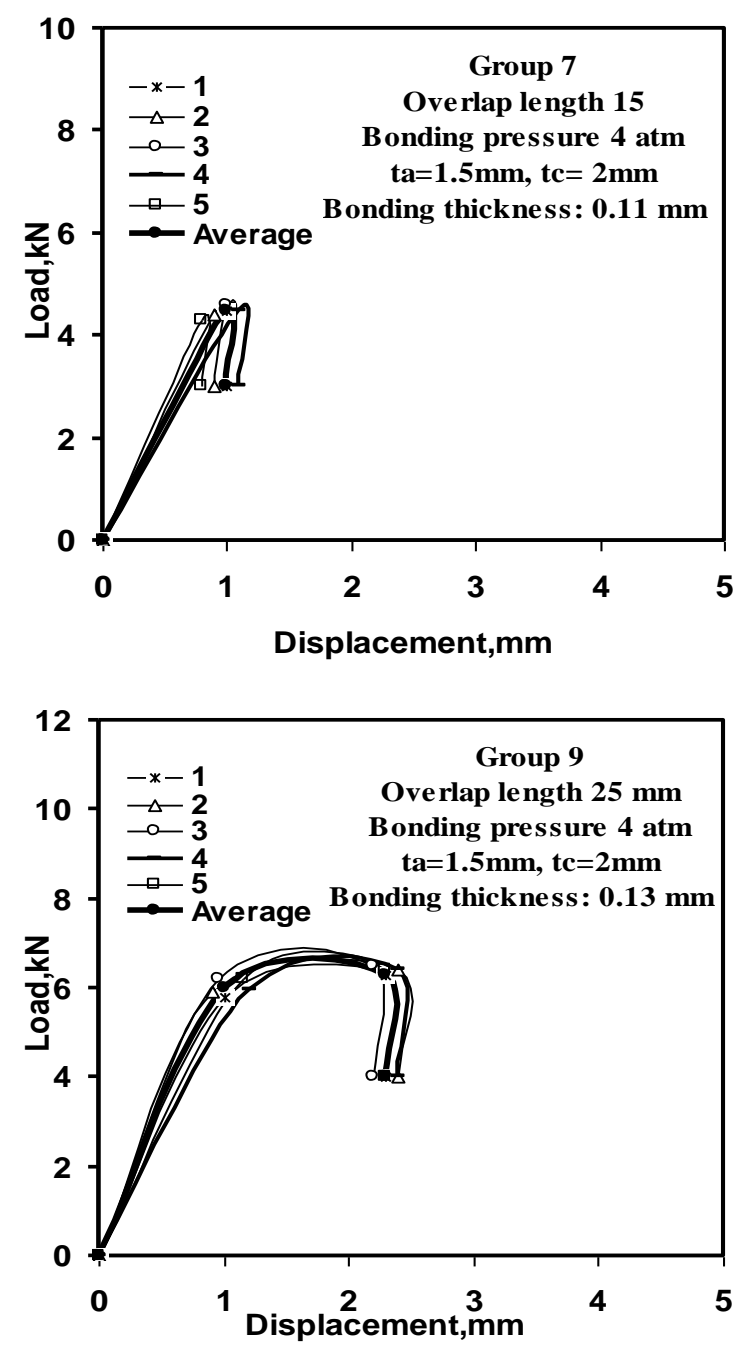

The edge of the bonded area plays a more important role in transferring the external load compared to the inner bonded area. Although the overlap length is increased, the edge area of the bonded area does not vary; hence, the carried load does not change substantially. This suggests that, increasing the overlap length to obtain a higher failure level for a bonded joint is efficient only within a limited range
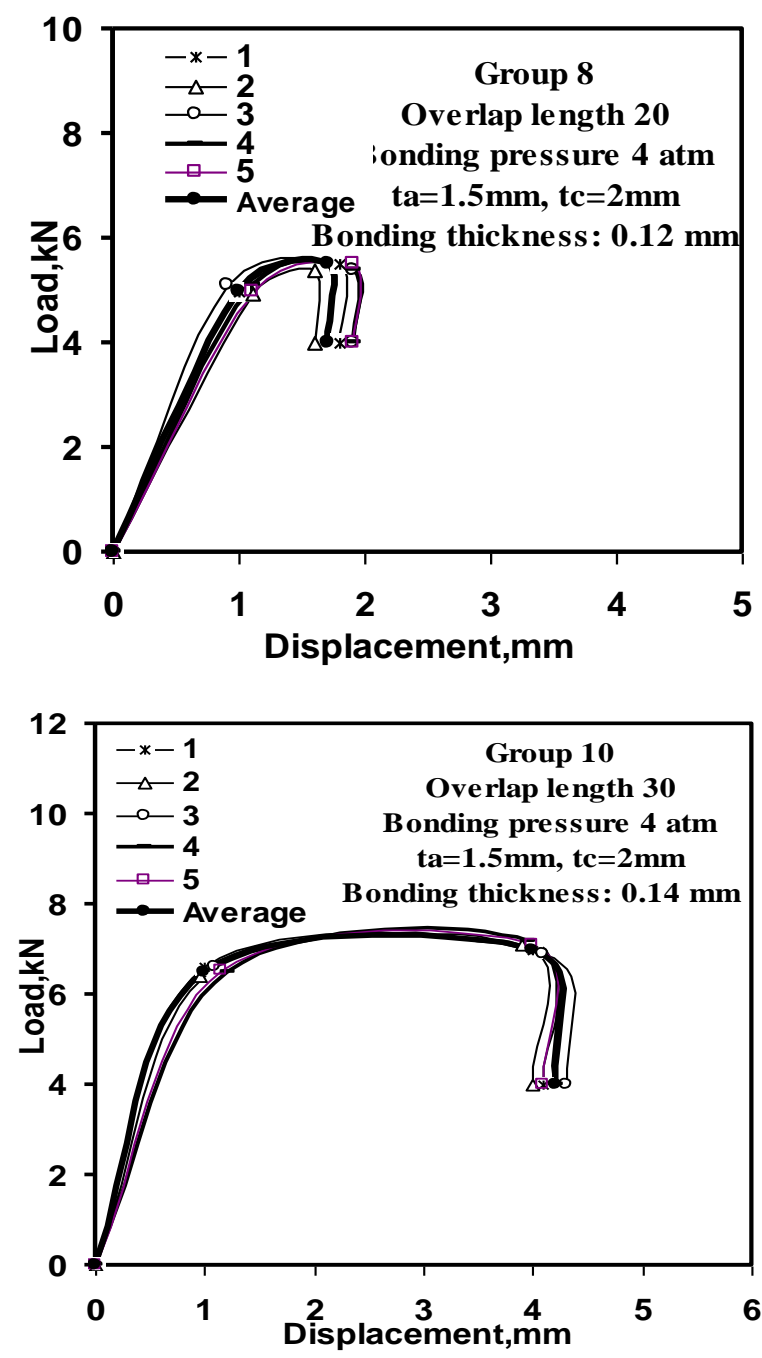

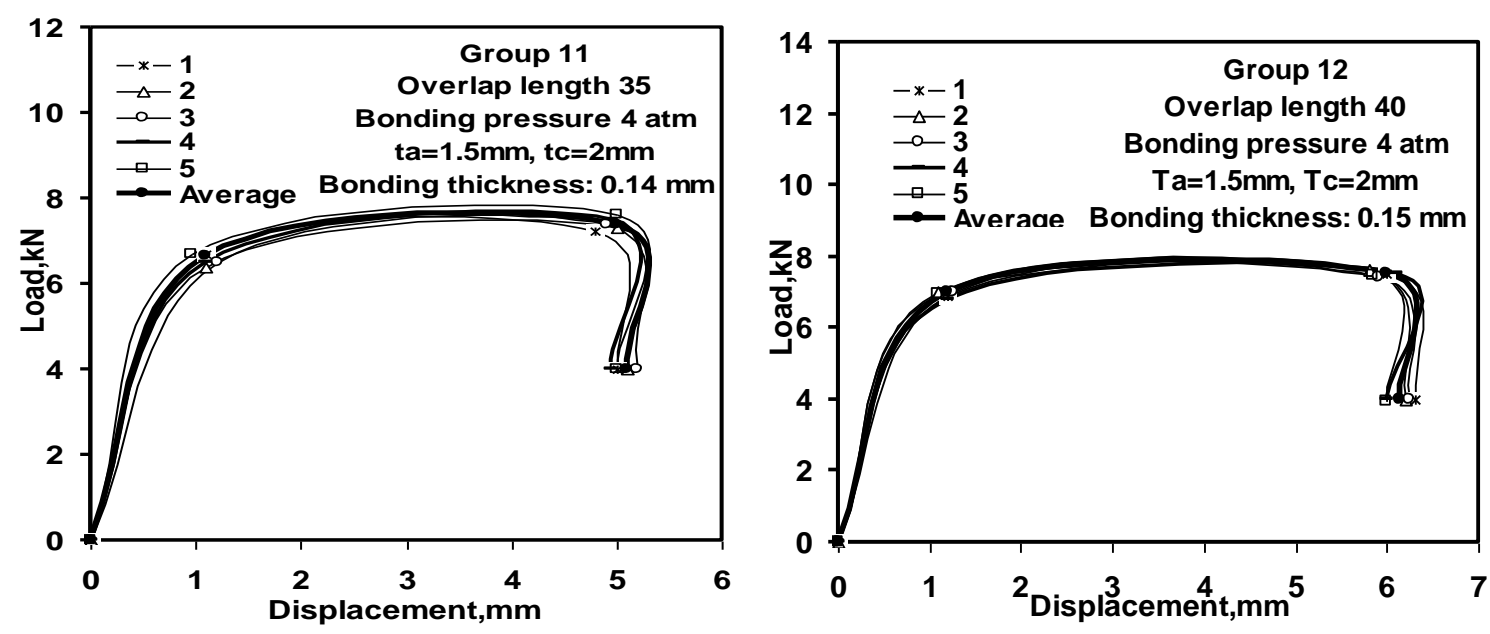

Fig.5. Load-displacement curve of bonded joints with different overlap length
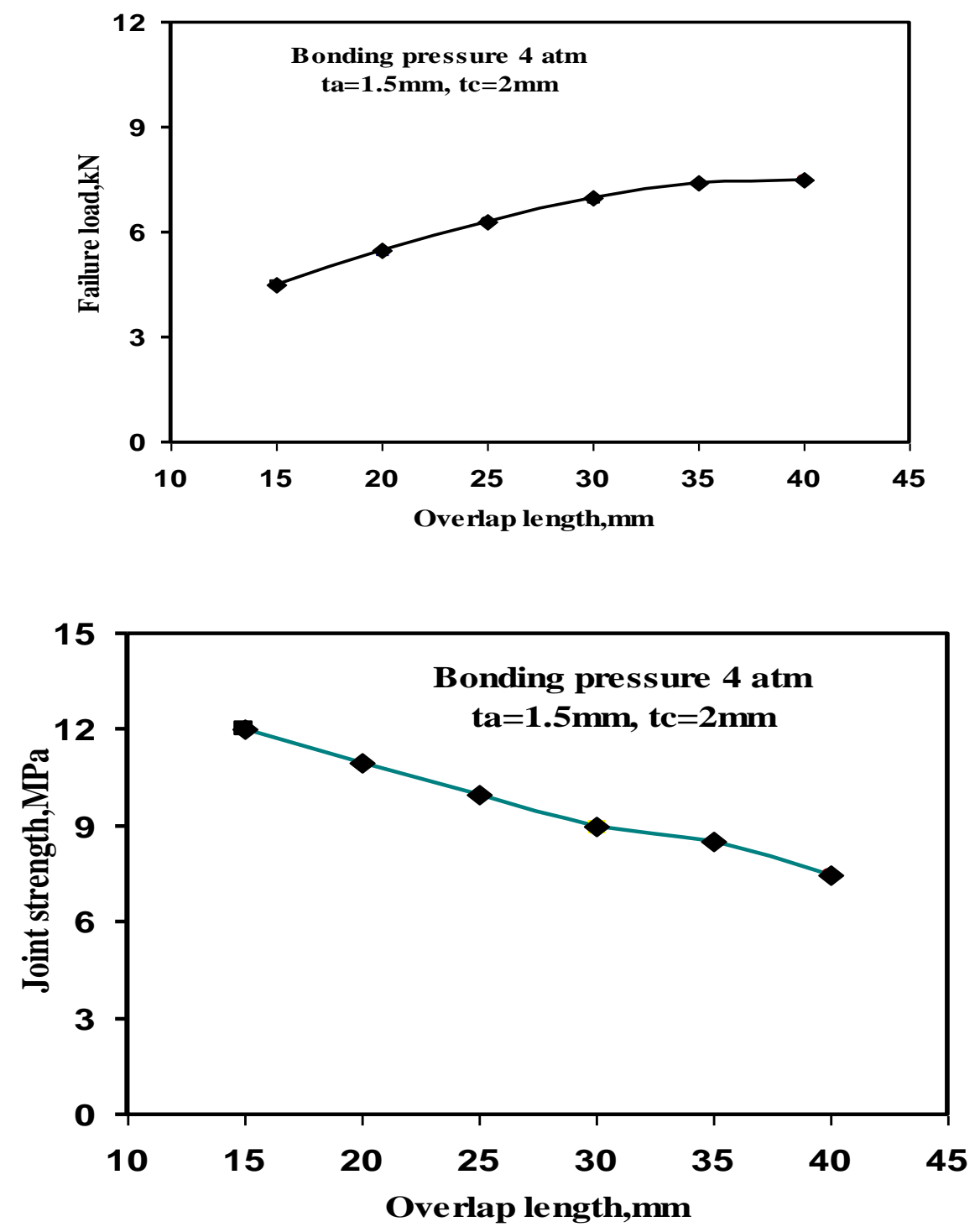

Fig.6. Bonded joint strength and failure load vs. overlap length 


\subsection{Effect of Adherent Thickness}

The effect of the adherent thickness has been investigated by increasing the aluminum adherends thickness from $1.5 \mathrm{~mm}$ to $3 \mathrm{~mm}$ and the composite adherent thickness from $2 \mathrm{~mm}$ to $4 \mathrm{~mm}$. Figure 7 shows the load-displacement curves of thick specimens of groups 13 to18, with various overlap lengths $(20,25,30,35$, and 40$)$ and adherent thickness $\left(t_{c}=4 \mathrm{~mm}, t_{a}=2 \mathrm{~mm}\right)$. In all cases, the relation between the applied load and displacement is approximately linear up to the maximum failure load, and drops suddenly at failure. The joint strength is plotted against the overlap length, as shown in Fig. 8. It is obvious that, the strength of a thick joint is $11-25 \%$ higher than that of a thin joint.
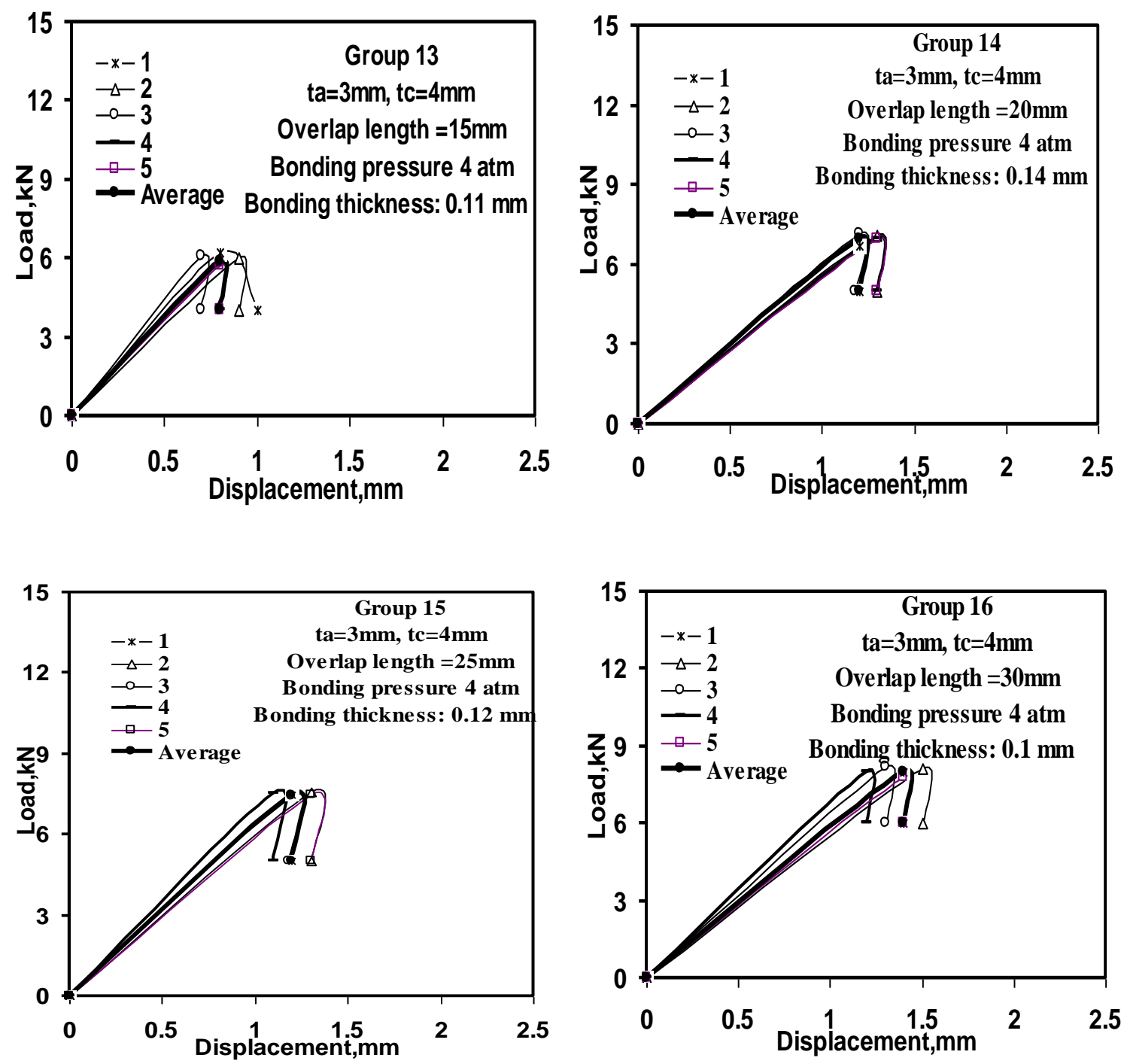

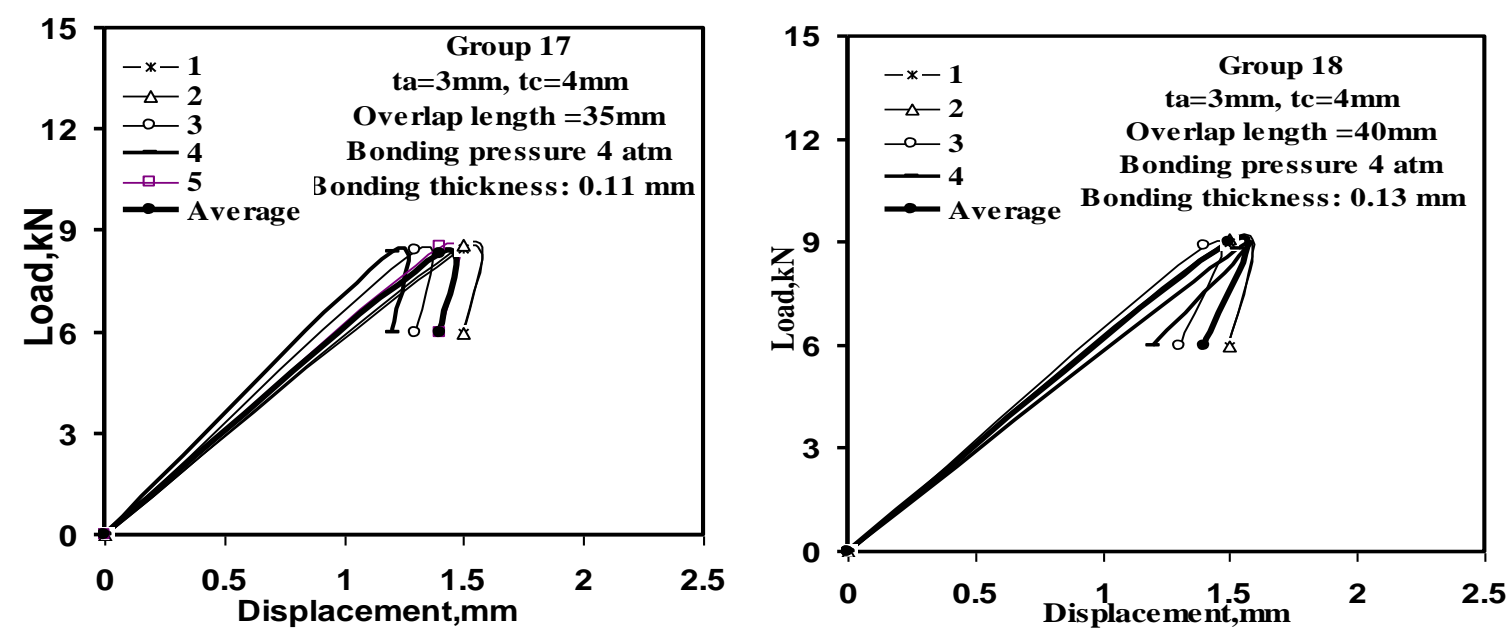

Fig.7. Load-displacement curve of thick specimens.

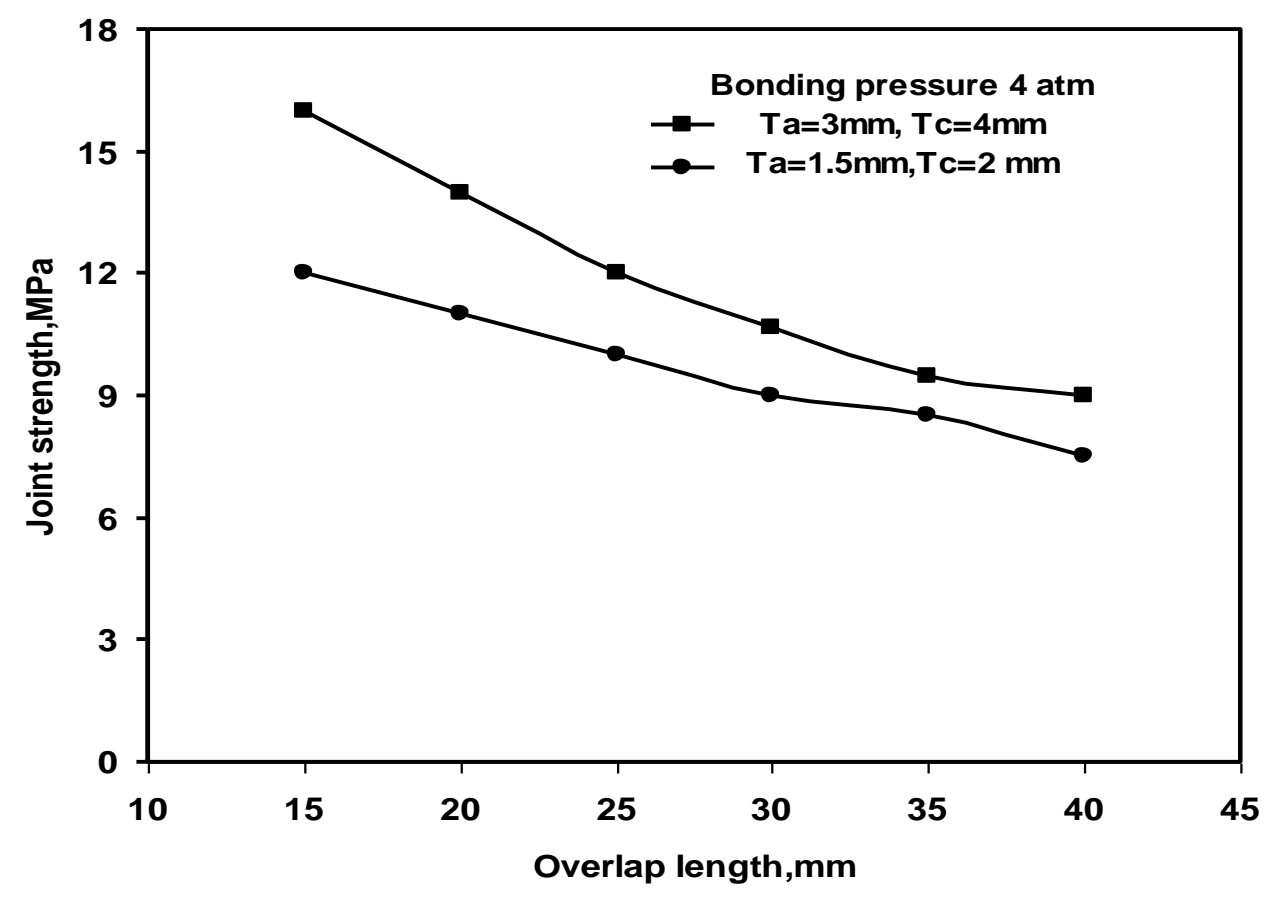

Fig.8.Joint strength of thin and thick specimens vs. overlap length

\section{CONCLUSION}

On the basis of the present results, the followings could be concluded:

1. The joint strength and the failure load increase with the increase of the bonding pressure.

2. The bonding pressure of 4 atm seems to be suitable for bonding GFRE composite to aluminum.
3. The load-displacement relationship is linear up to failure for joints with small overlap length, or begins linear and followed by a nonlinear relationship till failure for specimens with greater overlap lengths.

4. Increasing the overlap length increases the failure load and decreases the strength of the joints.

5. Larger adherent thickness leads to a higher joint strength and failure load. 


\section{REFERENCE}

[1] Afendi.M. and Teramoto.T." Fracture toughness test of eposy adhesive dissimilar joint with various adhesive thickness", J. Soljd Mechanics and Materials Engineering. Vol., 4.PP. 9991010, 2010.

[2] Seong.M. Kim.T., Nguyen. K., Kweon. J. and Choi.J. "A parametric study on the failure of bonded single-lap joints of carbon composite and aluminum" Composite Structures, Vol. 86, PP. 135-145, 2008.

[3] Kahramana. R., Sunarb. M., and Yilbas. B., "Influence of adhesive thickness and filler content on the mechanical performance of aluminum single-lap joints bonded with aluminum powder filled epoxy adhesive." J Mater. Process Technol. Vol. 205. PP.183-189, 2008.

[4] Schon.J. and Starkov, R., "Fatigue of joints in composite structure" In: Harrys B. Editor. Fatigue in composites. Wondhead Pubishing Limited, PP. 621-643., 2000.

[5] Baker.A. A. and Chester.R.J." Minimum surface treatments for adhesively bonded repairs". Int.J. Adhes. Vol. 12. PP.73-78, 1992.

[6] Rhee. K.Y. and Yang.J." A study on the peel and shear strength of aluminum/CFRP composite surface-treated by plasma and ion assisted reaction method." Comp. Sci. Technol., Vol 63, PP.33-40, 2003.

[7] Hart. S.," A hesively-bonded single-lap joints", NASA CRI 12236; 1973.

[8] Hartis. S., and Adams. R.D.," Strength prediction of bonding single-lap joints by nonlinearity finite element methods "Int. J. Adhes. Vol 4. PP. 65-78, 1984

[9] Mazumder. S.K. and Mallick. P. K., "Static and fatigue behavior of adhesive joints in SMC-SMC composite." Polymer Composite. 19(2): PP ;139146, 1998.

[10]Li. G., Lee. S.P. and Thring. R. W., "Nonlinear finite element analysis of stress and strain distributions across the adhesive thickness in composite single-lap joints." Compos Struct. Vol.46.PP. 395-403, 1999.

[11] Karious. K.C. and Matthews. F. L., "Strength and failure modes of bonded single-lap joints between cross-ply adherend." Composites.24 (6) 475-484, 1993.

[12] Kim. K.C., Yoo. J.S., Yi. Y.M. and Kim. C.G.," Failure mode and strength of uni-direction composite single-lap bonded joints with different bonding methods." Compos. Struct.Vol.72. PP.477-485, 2006.

[13] Quaresimin. M., and Ricota. M., "Live predication of bonded joints in composite materials" Int.J.Fatigue.Vol.28.PP.1166-1176. 2006.

[14] Azari. S., Papini. M., and Spelt. J. K.," Effect of adhesive thickness on fatigue and fracture of toughened epoxy joints - Part I: Experiments and finite element modeling." Fract. Mech. Vol.78.PP. 138-152. 2011

[15]Dasilva. L. F.M., Carbas. R.J.C., Critchlow. G.W., Figueiredo. M. A.V. and Brown. K., "Effect of material surface treatment and environment on the shear strength of single lap joints." Int. J. Adhes. Vol. 29. PP. 621-632, 2009.

[16] Azari. S., Papini. M., Schroeder. J.A. and Spelt. J.K., "The effect of mode ratio and bond interface on the fatigue behavior of a highlytoughened epoxy." Fract.Mech.Vol.77. PP.395414, 2010.

[17] Azari. S. Papini. M. Schroeder. J. A, and Spelt. J. K.," Fatigue threshold behavior of adhesive joints." Int. J. Adhes.Vol.30. PP.145-159, 2010.

[18]Du. J., Salmon.F.T. and Pocius.A.V.,"Modeling of cohesive failure processes in structure adhesive bonded joints." J. Ahes. Sci. Technol. Vol. 18(3).PP.287-299, 2004.

[19] Apalak.Z.G. and Apalak. M. K., "Progressive failure modeling of an adhesively bonded unidirectional composite single-lap in tension at the mesoscale level 1." Thermo. Comp. Mater. Vol.19.PP.671-702, 2006.

[20] Kim. K.C., Cho. C.R., Yi. Y.M. and Kim. C.G.," Failure mode and strength of uni-direction composite single-lap bonded joints 1. Failure prediction." J Korean. Soc. Compos. Mater.Vol.15. PP.1-9, 2005.

[21] Owens. J. F.P. and Lee. S.," Stiffness behavior due to fracture in adhesively bonded compositeto-aluminum joints 2-.Theoretical model" Int J. Adhes. Adhes.Vol.20.PP.47-58, 2000."

[22] Shin. K.C and Lee. I. J., "Prediction of the tensile load-bearing capacity of a co-cured single-lap joint considering residual thermal stresses." J. Ahes. Sci. Technol .Vol.14 (13) .PP.1691-1704, 2000. 